\title{
SHIFTING GENDER IN ELECTRONIC MUSIC: DIY AND MAKER COMMUNITIES
}

\section{In print:}

Richards, J. 2016. Shifting Gender in Electronic Music: DIY and Maker Communities. Contemporary Music Review. 35(1)

\section{DOI}

10.1080/07494467.2016.1176771

John Richards

Music, Technology and Innovation Research Centre

De Montfort University

Leicester

LE1 9BH

$\mathrm{UK}$

+44(0)1162078269

jrich@dmu.ac.uk

http://www.dirtyelectronics.org

\section{Bio}

John Richards explores the idea of Dirty Electronics that focuses on shared experiences, ritual, gesture, touch and social interaction. In Dirty Electronics process and performance are inseparably bound. The 'performance' begins on the workbench devising instruments and is extended onto the stage through playing and exploring these instruments. Richards is primarily concerned with the performance of large-group electronic music and DIY electronics, and the idea of composing inside electronics. His work also pushes the boundaries between music, performance art, electronics, and graphic design and is transdisciplinary as well as having a socio-political dimension.

\section{Shifting Gender in Electronic Music: DIY and Maker Communities}

\begin{abstract}
The rise in DIY and maker communities that has taken place over the last decade, including the growth of Hackspaces, Fab Labs and Maker Spaces, is not just about making: at its core it is a political development. It has been concerned with the empowerment of the individual in global, corporate societies, and with democracy on many different levels, gender included. There has been significant crossover between crafting communities such as Etsy and hackspaces. Make Magazine and Maker Faires have brought practical projects and arts and crafts activities alongside 'tech' in a neo-renaissance arts/science mash-up. Traditional roles and stereotypes have been questioned in the process. Electronic music has also been influenced by these cultural phenomena. In this article, DIY and maker communities and a maker's ethos will be discussed in relation to issues of gender imbalance in electronic music as they exist particularly within academic institutions in the UK.
\end{abstract}

Keywords: Music technology, gender, DIY, maker communities, electronic music, crafting

There appear to be deeply rooted prejudices and biases concerning music technology courses in relation to gender prior to point of entry on to degree programs: very few females apply to 
study music technology in the UK. The result, as discussed by Born and Devine (2015), is a subject area with a demographic that is 'overwhelmingly male' (nearly $90 \%$ ). I have found myself in the position of working both inside and outside of the academy. On the one hand, as an academic at De Montfort University, Leicester - one of the institutions from which critical data has been drawn to substantiate Born's and Devine's argument-I have witnessed the growing pains of music technology as an academic subject. I have also been caught-up in the data. And, on the other hand, as Dirty Electronics, a non-academic music and performance project, I have had the opportunity to run workshops and participatory events and to perform at many different places from large arts and educational institutions to independent arts spaces, small clubs and bars. ${ }^{1}$ Consequently, I have become increasingly interested in the tension that exists between participation in what I will loosely call electronic music within and without the academy.

What has become clear is that gender imbalance within the academic subject area of music technology is not, per se, a question of content. For example, the same workshop or activity can be run in various contexts with radically different gender balances. Through my own practice as Dirty Electronics, I also began to make a number of observations concerning gender, and started to consider whether, and in what ways, DIY and maker communities have or have not helped to address issues of gender imbalance in electronic music. In the first instance, I raised this question in relation to electronic music both inside and outside the academy.

It is important to note that my practice is not primarily concerned with gender issues. Some qualification of this practice is also required. Central to my work is the idea of participation (as discussed below), not as an added bolt-on, but as a core philosophical principle. The 'participant' is often a result of an open call, open to anybody, male or female; ideally this brings in a mix of participants who reflect the wide diversity of society at large. I often quote Joseph Beuys' notion of social sculpture and Cornelius Cardew's idea of music as an 'assembling for action' as points of reference (Cardew, 1969, p. 617; cf. Beuys, 1974; Richards, 2012, 2013). Participation is seen as a way of shaping the artwork/music from the ground up. This is often achieved through collectively building instruments/sound objects that become a tabula rasa for exploring ideas such as delegated performance (as described by Claire Bishop in Artificial hells: participatory art and the politics of spectatorship) - where an 'invented' instrument is placed in the hands of the non-expert in an attempt to find authenticity in a work (Bishop, 2011). My practice is often didactic focusing on working together in large groups and making sound and music in such contexts, but not explicitly about learning electronics. The idea of Dirty Electronics was intended, furthermore, to highlight a physical hands-on approach to sound making, and to question the body in relation to technology. Part of the intention of the project was also to address physical labour and materiality in a digital age. If there were any subconscious agendas regarding gender, they were to attempt to breakdown gender stereotypes or adopt a post-gender position as described by Donna Haraway in her 'A Cyborg Manifesto' (Haraway, 1991).

Dirty Electronics, although focused on music and performance, has socio-political concerns, and has been part of a zeitgeist that reflected the rise in DIY and maker communities that has taken place over the last decade. Hackspaces and Fab Labs and Maker Spaces have not just been about making: rather, at their core they are political. Such organisations and their members have been concerned with the empowerment of the individual in global, corporate societies, and with democracy on many different levels, gender included. This view has been emphasised by Mister Jalopy's 'If you can't open it, you don't own it: a Maker's Bill of Rights to accessible, extensive, and repairable hardware' (Jalopy, 2005). The politics of hacking are also expounded upon by McKenzie Wark in $A$ Hacker Manifesto where he sets the hacker (bringer of new concepts and information) against 
the 'vectoralist class' (cooperate giants) who capitalise on the innovations of hackers and hold the power and restrict the freedom of information across various pathways and networks (Wark, 2004). Furthermore, Alex Galloway has discussed issues of alienation from society due to commodification and the idea of returning to more authentic and sincere existences through making (Galloway, 2012). At times in my own work, a tension has existed between a kind of DIY production and empowering individuals to make their own electronic devices for sound and music. For example, the Mute Synth I and II designed and made in collaboration with the record company Mute Records (currently an independent record company but previously a subsidiary of EMI) is arguably a product; whilst with certain devices, such as the Sudophone, there has been an insistence on DIY with free information regarding making and construction being made available online and the shunning of sales. ${ }^{2}$ In many respects, these tensions are also indicative of a maturing DIY community where a continuum between the hacked (abstract) and product, as discussed by Wark, exists (Wark, 2005).

This article draws on observational and statistical data from participatory and public events, and looking at music technology-related activities outside of educational establishments. This has involved looking back over mailing-lists and communications with co-organisers and participants. The participant in this context is also seen as representative of a community from which data can be drawn. As a result, as mentioned above, I have been able to view my own practice in the context of the DIY community at large, using more traditional research methods to source data. Although the research in this article examines gender in, broadly speaking, maker spaces, there is an attempt to look more specifically at the relationship of these spaces to sound and music.

\section{Maker Communities}

The Maker Media group, which includes Make Magazine and Maker Faire, has undertaken market research into the demographics of magazine subscribers and Maker Faire attendees. ${ }^{3}$

It is important to note that there is a strong sound and music interest represented by this group with many of Make Magazine's self-build projects targeted at musicians, the projects of Make author Colin Cunningham being prime examples. ${ }^{4}$ Although the research is focused on the United States, the magazine and its online presence are seen as having a wider international impact. Maker Faires also take place internationally. The Maker Market Study and Media Report, 2012, was an attempt 'to provide in-depth knowledge about the maker community, their collaborative approach to making, and their use of tools and technology' and to 'shed light on the attitudes and behaviors of makers' (Maker Media, 2012). The Report showed that Make Magazine subscribers, readers and Faire attendees were $81 \%$ male, $19 \%$ female. Further market research has been undertaken by the group, looking more specifically at the attendees of Maker Faires. The Attendee Study Maker Faire Bay Area 2014 showed attendees to be $70 \%$ male, 30\% female (Maker Media, 2014a), whilst the Attendee Study World Maker Faire 2014 (New York) was 66\% male, 34\% female (Maker Media, 2014b). Whereas these statistics do not show a gender parity within maker communities, the gender balance is more equal than within the academic subject area of music technology as illustrated by Born et al (ref).

Hackspaces/Hackerspaces and Fab Labs (fabrication laboratories) have also contributed significantly to the rise of maker communities. From the mid 1990s, hackspaces began to emerge as physical locations where enthusiasts could meet, share tools and ideas and learn through making and taking things apart. At the start of the millennium, the concept of the hackspace proliferated worldwide. Similarly, Fab Labs, initially set up through initiatives undertaken at MIT, developed globally through the Fab Foundation. ${ }^{5}$ These Labs focused more on the democratisation of technology and the provision of community-based spaces for laser cutting, 3D printing and CNC milling. ${ }^{6}$ In 2010, a survey undertaken by 
Schlesinger et al. (2010) looked at hackspaces in the areas of Boston, New York and Silicon Valley. The results showed a range of gender mixes among the participants, from the lower end, 15\% women (Hacker Dojo) and 20\% to 30\% women participants (NYC Resistor), to the higher end, 40\% women (BUILDS) and 50\% women participants (Sprouts). Further research on gender and Fab Labs has been undertaken by Tanja Carstensen and the SKUDI (Subject Formations and Digital Culture) research project. ${ }^{7}$ Cartensen's chapter 'Gendered FabLabs?' in Walter-Herrmann's and Büching's FabLab: Of Machines, Makers and Inventors (2013) looks at data from St Pauli's Fab Lab, Hamburg and twelve other international Fab Labs (Carstensen, 2013). Carstensen concludes that Fab Labs, despite being often male dominated, are positive developments in terms of encouraging a more democratic understanding of technology, which in turn has helped to address issues of gender imbalance relating to technology in general.

In 2009, the UK Hackspace Foundation was formed to develop hackspaces in the UK. ${ }^{8}$ When starting a hackspace, the Foundation's philosophy is: 'Don't push any specific angle, e.g. electronics or software, just be open to people learning, making and breaking things' (UK Hackspace Foundation, 2015). Hackspaces and Fab Labs are run for and by their members, in most instances with no agenda regarding what is hacked or fabricated. Consequently, this tends to produce regional variations in terms of demographics. There are subgroups, including music hackspaces. Jean-Baptiste Thiebaut of the London Music Hackspace has provided Facebook data showing that out of 1,527 likes for the page, 29\% are female (Thiebaut, 2015). These figures are in line with those discussed earlier in relation to the Maker Media market research and gender within maker communities, showing a female demographic of approximately a third. Data from the London Music Hackspace, with music and technology being critical, shows a greater female involvement in 'music technology' than that of academic music technology courses within the UK.

Jenny Walklate, former director of the Leicester Hackspace, UK, is more cautious about hackspaces becoming liberated gendered spaces:

I suspect that, broadly, there is at least an ideal within a large sector of the maker/hack community to gain a better gender balance, but I do think ... that there is still a very vocal and powerful (and biased, perhaps unintentionally) core of Straight White Middle-Aged Men who don't think women belong or have the same capacities with tech as men (Walklate, 2015).

Furthermore, given the gender balance reflected in the hackspaces discussed above, it is perhaps not surprising that specific feminist hackspaces have been established, for example, Double Union (in San Fransico), FouFem (in Montreal) and Mz Baltazar's Laboratory (in Vienna).

Outside of global organisations such as Hackspace and Fab Foundation, many independent maker spaces have emerged that have been aware of gender-related issues. STPLN Fabriken in Malmö, Sweden is an archetypal maker's space that is 'available for anyone who wants to create and build things, produce cultural events or experiment with project designs' (STPLN, 2015). STPLN operates a membership fee policy. Director Caroline Lundholm feels that the maker movement is still male dominated, although particular activities show different rates of gender participation:

In [STPLN] Fabriken, our current membership base is about 70/30 male/female, but since STPLN has different sorts of activities within the house we can balance the total turn out to almost 50/50 [in terms of gender balance]. We also know that open activities like 'Open Lab' are more popular amongst male participants, whilst 
organized workshops attract women to a larger extent. During workshops the participants are usually 60/40 female/male. (Lundholm, 2015)

Deborah Hustic, director of the independent Radiona.org (Association for Development of 'do-it-yourself' Culture in Zagreb, Croatia), has taken an 'all inclusive' approach to its membership:

The lab itself was from the beginning all inclusive with no special marking or tagging subcultures because [in] that way inclusion wouldn't make sense. By expecting everything equally you don't need to mark it afterwards publicly, it's simply something you put into practice and you find normal. All inclusive is normality for us. (Hustic, 2015)

Limewharf in London, founded by Thomas Ermacora, is an independent space that is partfunded by membership fees. In 2014, Limewharf opened its Machines Room as a maker's space with fabrication facilities. Its current membership is relatively balanced in terms of gender with 56\% male, 44\% female (Vibert, 2015). Ermacora states bluntly, 'In short it is a niche driven industry with tribes that are occasionally gender based. Important for gender questions is to have operators and players in the makertech scene target and balance tribes in their offering and strategies' (Ermacora, 2015).

Etsy, an online marketplace for arts and crafts, represents a particular makers' tribe. ${ }^{9}$ There is less of an onus on tech with Etsy, and many of its top sellers are in the categories of jewellery, knitting and clothing. The Etsy Sellers Survey, 'Redefining Entrepreneurship: Etsy Sellers' Economic Impact', states that Etsy's sellers are 88\% female (Esty, 2013). Despite the apparently stereotypical gendered interests of Etsy's sellers, and its arts and crafts orientation, Etsy represents a community empowered to make. Later in the article I consider the implications of diversity within maker communities and how the populations of such communities may overlap and interchange. The article, however, is less about the demographics of hackspaces, Fab Labs or Etsy sellers per se, and more about how a makers' ethos can impact on gender representation in the field of electronic music-whether through a Man Shed, a feminist hackspace or Stich 'n' Bitch knitting groups.

\section{Dirty Electronics and Workshopping}

In 2003, I began working as Dirty Electronics. My aim was to explore some of the ideas I have highlighted above, and to employ a makers' aesthetic in the specific area of sound and music. Data relating to gender and participation can be sourced from the workshops that I have undertaken as Dirty Electronics from 2008 to the present. This has been an especially intense period with regard to workshopping. Since 2012-13, I have focused more on the participatory 'event' and less on the 'workshop', since the term workshop is potentially narrow in scope, and I have wanted to emphasise performance within a holistic practice. So latterly there has been some shift in relation to the content of these workshops (to be discussed in more detail later). Information from the earlier workshops was not collected as 'data', but as mailing-lists aimed at keeping interested participants informed of future workshops. The data is not therefore exhaustive, but it does provide some valuable information relating to demographics. There is a distinction made between workshops given within academic institutions and those outside. I have been invited to run workshops and events within academia on a range of courses spanning the arts. These courses have included product design, interaction and information experience design, creative media, fine art and sound art, as well as courses with art students in general working with sound, dance and movement, music in music departments and conservatories, and music technology courses. 
Data has also been collected from online sources that include website views, instrument sales and social media related to these workshops and my own activities. The workshops that have taken place outside academia have been hosted and organised primarily by arts organisations and music festivals that cannot be considered truly independent: they may be state funded or have specific sponsors. Each of these organisations and festivals, discussed later in more detail with reference to specific data, have their own demographics that could be considered influential on the gender balance of Dirty Electronics workshops.

Between 2008 and the present, I have run 58 Dirty Electronics workshops, an average of seven per year. The number of participants per workshop ranged from as little as two to seventy-one. Over this period, the total number of participants was 891 . The workshops took place internationally, in places ranging from the UK and Europe to the US, China, and Japan. For the purposes of this article, I focus mainly on data from UK workshops, although data from non-UK workshops will also be considered to highlight more general issues relating to gender and electronic music. The Dirty Electronics website, scrutinised through Google Analytics, provides some gender-related data. The website provides: basic information on upand-coming events; articles, instrument documentation and schematics; music and video excerpts/links; and an online shop for a limited range of pre-made devices/instruments. Over the last twelve months, there has been an average of 695 website users per month; the gender split for these views is $45 \%$ female, 55\% male (Dirty Electronics, 2015).

As mentioned in the introduction, similar content presented in different contexts has produced marked differences in participant demographics. Workshops that I have undertaken, hosted within a music technology program at a higher education or academic institution, share similar male/female balances to the data presented by Born and Devine (2015), with approximately $10 \%$ of participants being female. However, this is not the case when workshops are run in non-academic institutions. I will present some examples below focusing on UK-based events.

Dirty Electronics' Solder a Score was held as part of the Institute of Contemporary Arts's Live Weekends: Notation and Interpretation. ${ }^{10}$ A detailed account of this participatory event can be found in the ICA's magazine Roland (Richards, 2011). The event consisted of workshops that ran over three days leading to a public performance with workshop participants. Each participant built a modular feedback circuit that consisted of a specially commissioned artwork-printed circuit board. A participation call was sent out by the ICA through their mailing-list and social networks. Participation was free. There were 48 attendees, of which $38 \%$ were female. Of course, the demographics of ICA attendees in general need to be considered here; however, a similar participant demographic can be found whenever Dirty Electronics workshops have been hosted by art leaning organisations and institutions. For example, 'Soundobject', an exhibition organised in an independent gallery by the Royal College of Art, London, included a Dirty Electronics workshop open to the public, of which $43 \%$ of the participants were female. ${ }^{11}$

Dirty Electronics workshops held at music festivals have also produced different demographics to those run within the academy and labelled as 'music technology' events. Many music festivals have day and weekend passes and programs geared towards particular audiences. The gender balance of Dirty Electronics workshops run at these festivals is therefore biased by the festivals' demographics. Nevertheless, the data shows there is a distinction between the gender balances between these non-academic events and when similar workshops are run within academic music technology programmes. With a focus on electronic music, it is not surprising that I have been invited to festivals specialising in this area. The Short Circuit Festival is a weekend event held annually at London's Roundhouse, and in 2011 the Dirty Electronics workshop at the festival had $27 \%$ female participation. ${ }^{12}$ Supersonic Festival, Birmingham, has a leaning towards noise, metal and experimental music 
and is in its twelfth year. Dirty Electronics workshops ran there in 2009 and 2011, and female participation in both Dirty Electronics workshops was approximately $20 \%{ }^{13}$

Looking briefly outside the UK, Sonar, Barcelona has become one of the world's leading festivals of electronic music, initially focussing on dance music but also developing a daytime program exploring more experimental music and music technology related content. In recent years, there has been a growth of workshops and participatory events at the festival. Dirty Electronics have run two workshops at Sonar in 2012 and 2013 with a third planned for 2015. The past workshops were designed as opportunities for participants to work directly with electronic sound through building hand-held synthesisers. The workshops were short in duration, about two hours long, and catered for larger groups than normal for Dirty Electronics. In 2011, there was a 20\% female participation, whilst of the 71 participants in 2012 , this rose to $25 \%{ }^{14}$ A significant contribution to the festival in recent years, reflecting the rising interest in the DIY/handmade music community, has been the introduction of the Music Hack Day. Since 2006, the Music Hack Day has become a 'global initiative' with regular participatory events in which hackers and would-be hackers are invited to conceptualise and create work. ${ }^{15}$ Sonar recently reported that in 2014, female enrolment in the Barcelona Music Hack Day was 10\%, with this figure rising to 20\% for the 2015 event (Sonar $+\mathrm{D}, 2015)$.

In terms of other notable data, some Dirty Electronics workshops have been held at music festivals that do not specialise in electronic music, with Dartington International Summer School being a good example. This is an annual festival lasting about a month that caters for a range of musics. ${ }^{16}$ Dirty Electronics workshops ran at Dartington from 2012 to 2014, and over this three-year period there was a $45 \%$ female participation. ${ }^{17}$ There have also been a number of Dirty Electronics workshops hosted by maker spaces and maker faires, an indicative example being Edinburgh Mini Maker Faire, in which 57\% of the participants were female. ${ }^{18}$ Looking closely at the demographics of Dirty Electronics workshops for the entire period presented above, and including events that took place in academic institutions, the greatest female participation has been in Japan, Hong Kong and China. Dirty Electronics workshops took place at Tokyo University of the Arts, Tama Art University and Tokyo Polytechnic University, and in all of them, the female participation rate was greater than $50 \% .{ }^{19}$ Workshops with creative media students at City University of Hong Kong exceeded $60 \%$ female participation; and a Dirty Electronics event curated by independent organiser Yan Jun and Zoomin' Night at the venue XP in Beijing had 47\% female participation. ${ }^{20}$ Why are parts of Asia producing these higher figures? This may be to do with, for example, China's one-child policy, or the way young women are encouraged into science and engineering subjects, or how arts courses are seen as being less gendered. But what is clear is that where music, sound and technology exist side-by-side in an arts or media setting, there is a better gender balance than in the academic subject of music technology.

\section{Gender Scripts and Making}

I want to look more closely at whether there is anything specific to DIY and maker communities that is helping to address issues of gender imbalance in electronic music; I also want to ask whether what is being made has implications with regard to gender. Is gender being imprinted in the very things that are made? Or do these objects have intrinsic gender characteristics? Much has been written on gender and technology, and on whether artifacts "incorporate a "gender script"' (Carstensen, 2013, p. 54). Anne-Jorunn Berg and Merete Lie, for example, who have undertaken feminist research on technology, state:

We were interested in new technologies because they offered an opportunity to study change. Studying technological development meant studying social change, and it was 
obvious to us that the field of social studies of technology included the possibilities of studying changes in gender relations (Berg \& Lie, 1998, p. 335).

Carstensen argues in turn: 'Usually, engineers and computer scientists produce technological objects. They often inscribed their unconscious ideas of gender roles into the artifact' (Carstensen, 2013, p. 59). In this view, any subconscious imprinting of gender onto material things is likely to come from the makers, affected by the wider culture. Consequently, DIY and maker communities - in as much as they respond to the desire to change the culture regarding gender and technology - offer at their very core opportunities to re-fashion the instruments from which electronic music is made, and therefore the music itself, as well as potentially re-casting the gender breakdown of those making the music.

With specific regard to Dirty Electronics workshops, I cannot claim that all of the devices produced are free of gender bias. Schematics, blueprints, circuit designs and musical ideas are often predetermined; however, as mentioned earlier, considerations relating to the democratisation of technology as well as general issues of participation have always been elements explored in the workshops. Many Dirty Electronics workshops and pieces focus on found objects (specific examples being Still for disposable cameras and Ear-Piece for discarded old telephones). These objects are found/owned by the participants, who are then often invited to explore the objects' sound and musical potentials through an object orientated ontology as expressed by Levi Bryant (Bryant, 2011). Whether or not there is an implied gender associated with these objects, the scope to develop them further as devices for musical use lies with their maker.

There have been many Dirty Electronics instrument designs that discard the archetypical control mechanisms associated with electronic musical instruments, for example, switches, dials, buttons, knobs, or faders. Such controls are arguably deeply embedded in a 'man and machine' paradigm. What has been of greater interest to me is to borrow ideas from the field of tangible user interface design — objects such as Durrell Bishop's Marble Answer Machine, which visualised a telephone answering machine system using marbles. ${ }^{21}$ This approach breaks down some of the layers of abstraction found within a system and esoteric design features often associated with computer technology. In Dirty Electronics, touch surfaces made from graphical printed circuit boards and circuits made using wire-wrapping techniques and nails as connection terminals have been used to offer alternative means for creating electronic circuits. Objects that afford a range of actions, from shaking to rolling and bowing, have also been explored.

There has been significant crossover between crafting communities such as Etsy and Hackspaces, and Make Magazine and Maker Faires have brought practical projects and arts and crafts activities alongside 'tech' in a neo-renaissance arts/science mash-up. ${ }^{22}$ Through the diversity apparent in these scenes, traditional roles and stereotypes have been questioned in the process. This has afforded within my own practice the opportunity to question what and how things are made, and I have consciously considered different construction techniques in the making of sound devices. Although the soldering iron and basic tools for electronics are frequently used, a range of tools and construction methods have been adapted for the workshops. They include the use of common hand tools like the hammer, screwdriver and scissors, and the use of materials such as paper, glue, conductive thread, wire wool, cardboard, scrap metal, wood and cloth. Dirty Electronics has involved deliberate attempts to take the electronics out of the 'lab' and place it in 'art' spaces - including galleries, dance studios, rehearsal rooms, concert halls and community centres. In this way, the artist or musician does not occupy a science space but, rather, technology and technological practices are brought to a familiar music rehearsal or performance space or neutral space (outside of space associated with music or science). An arts and crafts approach is placed alongside the 
scientific. Moreover, it has not always been primarily about making material things: since 2012, as mentioned earlier, there has been an emphasis on making performances. Participants have been challenged to work across the disciplines of science, arts and crafts, and the performing arts, and to explore the new territories created by these overlaps.

\section{Conclusion}

What the data presented in this article show is that, although gender stereotypes continue to exist in maker spaces and DIY communities, the content covered in some academic music technology courses can have a different and broader demographic, with a better gender balance, outside academic institutions. The data also point to a modest increase in female participation in certain areas relating to DIY music in recent years. The number of females involved in hackspaces and maker communities appears to be growing, and feminist hackspaces along with the women involved in developing music hackspaces suggest a growing political will to redress the gender imbalances that currently exist in academic subject areas such as music technology. The data also highlight how academic courses such as music technology constructed around narrow learning outcomes tend to deter widening participation, and with this female enrolment. Female participation in music and technology related activities seem to be healthier, according to the data, when presented in arts contexts. Where diverse approaches to and contexts for music and technology are provided, evidence suggests that gender discrimination is not intrinsic in music technology as a field of practices, but that it is subject to a range of wider cultural and sociological factors.

The word 'technology' continues to bring with it all of the gender stereotypes from the traditional STEM subjects (science, technology, engineering, and mathematics), as Susan Marling recently showed in her BBC Radio 4 program Britain's Hidden Talent: Women Engineers (Marling, 2015). Similarly, the use of the term 'music technology' has not helped gender demographics within electronic music in the UK. The sound artist Kanta Horio on his visit to De Montfort University was asked the question: What was it like to study music technology in Japan? His answer was that in Japan there was no such thing as the academic subject of music technology (Horio, 2010). What might be considered music technology in Japan is coming out of art colleges and universities of the arts. It is not so different in the UK. Sound art thrives on many arts courses, whilst courses covering new media, digital art and interaction design have embraced new approaches to sound and music that are less gendered than music technology degrees. The point is that, to encourage more female participation in electronic music, more pluralistic approaches must be taken, some of the most promising of which, I have argued, have been developing through DIY and maker communities. 


\section{References}

Berg, A.-J., \& Lie, M. (1995). Feminism and Constructivism: Do Artifacts Have Gender? Science, Technology, and Human Values, 20, 3, pp. 332-51.

Beuys, J. (1974). Joseph Beuys' Public Dialogue. In Willoughby Sharp (Producer), Electronic Arts Intermix.

Bishop, C. (2011). Artificial hells: participatory art and the politics of spectatorship. London: Verso Books.

Bishop, D. http://www.luckybite.com/home.html

Born, G., \& Devine, K. (2015). Gender, Education and Creativity in Digital Musics and Sound Art. Twentieth-Century Music, 12(2), forthcoming.

Bryant, L. R. (2011). The Democracy of Objects. Ann Arbor: Open Humanities Press.

Carstensen, T. (2013). Gendered FabLabs? In J. WalterHerrmann \& C. Büching, eds. FabLab: Of Machines, Makers and Inventors. Bielefeld: Transcript Verlag, pp. 53-64.

Cardew, C. (1969). A Scratch Orchestra: Draft Constitution. The Musical Times, Vol. 110, No. 1516.

Dartington International Summer School. https://www.dartington.org

Dirty Electronics. (2015). http://www.dirtyelectronics.org

Ermacora, T. (2015). Email to the author, 30 April.

Etsy. (2013). Redefining Entrepreneurship: Etsy Sellers'Economic Impact.

http://extfiles.etsy.com/Press/reports/Etsy_RedefiningEntrepreneurshipReport_2013.pdf

Fab Foundation. http://www.fabfoundation.org

Galloway, A. (2012). Garnet Hertz - Interview with Alex Galloway in Critical Making: Conversations. Hollywood, California: Telharmonium Press.

Haraway, D. (1991) A Cyborg Manifesto: Science, Technology, and Socialist-Feminism in the Late Twentieth Century," in Simians, Cyborgs and Women: The Reinvention of Nature. New York: Routledge, pp.149-181.

Horio, K. (2010). PACE Building, De Montfort University, Leicester. 11 March, 2010. Lecture.

Hustic, D. (2015) Email to the author, 28 May.

Institute of Contemporary Arts (ICA), London. Live Weekends: Notation and Interpretation 16-20 February 2011. http://www.ica.org.uk 
Jalopy, M. (2005) Owner's Manifesto. If you can't open it, you don't own it: a Maker's Bill of Rights to accessible, extensive, and repairable hardware in MAKE: 04: Music and Kits for the Holidays, p. 154.

Lundholm, C. (2015) Email to the author, 22 May.

Maker Media. (2012). Maker Market Study and Media Report: An In-depth Profile of Makers at the Forefront of Hardware Innovation. http://cdn.makezine.com/make/sales/MakerMarket-Study.pdf

Maker Media. (2014a). Attendee Study Maker Faire Bay Area 2014. June 2014

http://make-cdn.s3.amazonaws.com/make/advertising/MFBA\%202014\%20research\%20deck_FINAL.pdf

Maker Media. (2014b). Attendee Study World Maker Faire 2014. November 2014

http://make-cdn.s3.amazonaws.com/make/advertising/WMFNY\%202014\%20deck_Final.pdf

Marling, S. (Narrator). (2015, May 1). In Paul Smith (Producer), Britain's Hidden Talent: Women Engineers. BBC Radio 4.

Music Hack Day. http://musichackday.upf.edu/mhd/2015/

Richards, J. (2011). Lead \& Schemas. Roland: ICA Magazine. Issue 9

Richards, J. (2012). Collateral Damage. The Wire: Adventures in Modern Music. Issue 338.

Richards, J. (2013). Beyond DIY in Electronic Music. Organised Sound, 18, 3, pp. 274-281.

Schlesinger, J., Islam, M., and MacNeill, K. (2010). Founding a Hackerspace. BSc Thesis. Worcester Polytechnic Institute: US. Available at: https://www.wpi.edu/Pubs/Eproject/Available/E-project-122210-154836/

Sonar +D. (2015). Tweet, 12 May.

https://twitter.com/sonarplusd/status/598033174166446080

SKUDI (Subject Formations and Digital Culture). http://skudi.org

STPLN. (2015). http://stpln.se/about

Thiebaut, J-B. (2015). Email to the author, 5 May.

Vibert, T. (2015). Email to the author, 30 April.

Walklate, J. (2015). Email to the author, 5 May.

Wark, M. (2004). A Hacker Manifesto. Cambridge, MA: Harvard University Press.

UK Hackspace Foundation. (2015).

http://www.hackspace.org.uk/wiki/Starting_a_Hackerspace 
${ }^{1}$ Dirty Electronics. http://www.dirtyelectronics.org

${ }^{2}$ Information on the Mute Synth I and II and the Sudophone can be found at

http://www.dirtyelectronics.org

${ }^{3}$ Make Magazine. http://makezine.com.

${ }^{4}$ Collin Cunningham. http://makezine.com/author/collinmel

${ }^{5}$ Fab Foundation. http://www.fabfoundation.org

${ }^{6} \mathrm{CNC}$ (computer numerical control) milling is used for for precision cutting of various materials.

${ }^{7}$ SKUDI (Subject Formations and Digital Culture): http://skudi.org

${ }^{8}$ UK Hackspace Foundation: http://www.hackspace.org.uk

${ }^{9}$ Etsy. https://www.etsy.com

${ }^{10}$ Institute of Contemporary Arts (ICA), London. Live Weekends: Notation and Interpretation 16-20 February 2011. http://www.ica.org.uk

${ }^{11}$ Royal College of Art, London, Soundobject. (2015). An exhibition of work as a result of a collaboration between students from Information Experience Design and Design Products programmes at the Royal College of Art, London and Sonos, 47/49 Tanner Street, Bermondsey, London, 14-16 May, 2015. Dirty Electronics ran a workshop entitled Noisy Design with 7 participants. Through an open call, participants were invited to bring an object that could be 'transformed' into a soundobject. http://rcasoundobject.com

${ }^{12}$ This was part of Short Circuit Presents Mute at the Roundhouse, London, 13-14 May, 2011.

There were 15 workshop participants who built the Mute Synth (2011). More information on the Mute Synth can be found at: http://www.dirtyelectronics.org/docs/mute_synth.zip

${ }^{13}$ The Dirty Electronics Pinboard/4049 Study was built by 22 participants at Supersonic Festival, Birmingham, UK, 25 July, 2009. http://www.dirtyelectronics.org/docs/4049_study.zip; whilst the Mute Synth was built by 20 participants at Supersonic Festival, Birmingham, UK, 23 October, 2011. $\mathrm{http} / / / \mathrm{www}$.supersonicfestival.com

${ }^{14}$ The Mute Synth was built by 30 participants at Sonar, Barcelona, 15-16 June, 2012. In 2013, the Sonar 20th Anniversary Synth was built by 71 participants at Sonar, Barcelona, 13-15 June, 2013. More information on the Sonar 20th Anniversary Synth can be found at: http://www.dirtyelectronics.org/docs/sonar20th.zip

${ }^{15}$ Music Hack Day. http://musichackday.upf.edu/mhd/2015/

${ }^{16}$ Dartington International Summer School. https://www.dartington.org

${ }^{17}$ The average number of participants per year over the three years $(2012,2013,2014)$ was 13 . A range of projects was presented each year in a week-long workshop. Amongst others, the pieces Charge/Discharge and Ribbon \& Strings were built and performed. For more information see: http://www.dirtyelectronics.org/download.html

${ }^{18}$ Edinburgh Mini Maker Faire, Summerhall, Edinburgh, 7 April, 2013. There were 7 participants who built the Mute Synth.

${ }^{19}$ Tokyo University of the Arts, 4-6 November, 2009 - the Sudophone and Skull Etching were built by 12 participants; Tama Art University, Tokyo, 9 November, 2009 - the Skull Etching was built by 20 participants; and Tokyo Polytechnic University, 10 November, 2009 - the Skull Etching was built by 22 participants.

Skull Etching documentation: http://www.dirtyelectronics.org/docs/skull_doc.zip

Sudophone documentation: $\mathrm{http}: / / \mathrm{www}$.dirtyelectronics.org/docs/sudomini.zip

${ }^{20}$ City University of Hong Kong, 22 January, 2014. Bed of Nails workshop with 29 Participants.

Information on the Bed of Nails: http://www.dirtyelectronics.org/docs/Bed_of_Nails.pdf

Zoomin' Nights, Beijing, XP, 13 January, 2014. This was advertised as a pre-event to a Dirty

Electronics concert. Fifteen participants explored performance through ready-made instruments and

Dirty Electronics pieces. Some of the participants took part in the concert at the same venue the following day.

${ }^{21}$ Durrell Bishop: http://www.luckybite.com/home.html

${ }^{22}$ Etsy: https://www.etsy.com; UK Hackspace Foundation: http://www.hackspace.org.uk; Make Magazine: http://makezine.com. 